\title{
Study of 500 patients with limb joint osteoarthritis. I. Analysis by age, sex, and distribution of symptomatic joint sites
}

\author{
Janet Cushnaghan, Paul Dieppe
}

\begin{abstract}
Five hundred subjects with symptomatic limb joint osteoarthritis, who had been referred to a rheumatologist, were enrolled into a continuing study. They comprised 342 women (mean age 65.3) and 158 men (mean age 59.7), with a mean symptom duration of 15.4 years at entry. Only 31 patients $(6 \%)$ had symptomatic osteoarthritis of one joint alone; however, in a further $205(41 \%)$ the disease was limited to one site. One hundred and eighty two (36.4\%) had two sites affected and 82 (16.4\%) three or more sites of symptomatic osteoarthritis. Of 847 affected joints the most commonly involved were $349(41 \cdot 2 \%)$ knees, $254(30 \%)$ hands, and 161 (19\%) hips. Hip disease stood out as a separate entity, often occurring alone, and having a stronger male preponderance and different associations than osteoarthritis at other joint sites. Knee and hand disease were significantly associated in women. Obesity, hypertension, and Heberden's nodes were common. The number of sites affected, as well as the distribution, was strongly related to age as well as sex, suggesting that polyarticular osteoarthritis arises from slow acquisition of new joint sites in a non-random distribution. 'Generalised' osteoarthritis did not emerge as a distinct entity.
\end{abstract}

Osteoarthritis is the commonest form of joint disease. ${ }^{1}$ It is related to age, and an increasingly important health problem in an older, generally fitter, more health conscious society. Excluding the spine, the three joint sites most often affected are the hip, knee, and hand. ${ }^{2}$

Surprisingly little is known about osteoarthritis, which remains difficult to define, characterise, or assess. Epidemiological studies implicate six main risk factors: age, inheritance, obesity, trauma, abnormal biomechanics, and alterations in joint shape. ${ }^{34}$ Probably, however, differences exist in the relative importance of these factors in the two sexes, and at different joint sites. ${ }^{5}$ Clinical studies of osteoarthritis have largely been concerned with a single joint site, such as hip or knee disease, generally divided into two main categories - primary (no obvious cause) or secondary (an apparent predisposing factor identified). The cause of osteoarthritis is clearly multifactorial, however, and the distinction between primary and secondary disease is blurred. ${ }^{6}$ Most of the available clinical and epidemiological data are cross sectional, little being known about the natural history of this condition.

In 1985 we embarked on a prospective study of symptomatic osteoarthritis of the limb joints. This paper reports on cross-sectional data obtained at the time of patient recruitment, analysed by age, sex, and the distribution of symptomatic joint sites.

\section{Patients and methods}

Five hundred consecutive patients with limb joint osteoarthritis were recruited into the study. All had been referred to the rheumatology unit of the Bristol Royal Infirmary by local general practitioners or consultant colleagues. The diagnosis of osteoarthritis was made by one of the authors (PD) before study entry and was based on a combination of typical radiographic features (including joint space narrowing) plus symptoms and signs compatible with osteoarthritis (including pain related to use) in at least one limb joint. In all cases the osteoarthritis was considered to be the primary rheumatological problem, though those with other disorders were not excluded.

One observer (JC) interviewed all the patients according to a set protocol. Historical details included the age, sex, and occupation of all patients, the duration of joint symptoms and symptomatic joint sites at the time of the interview. The joint(s) considered by the patient to be the major or worst sites were noted. Details of symptoms (pain, stiffness, and disability) were collected and the Steinbrocker functional class recorded. Any previous trauma or surgery which might have predisposed to osteoarthritis, as well as the presence of any intercurrent disease, was noted. Current drugs used and any treatment, including use of aids and appliances, were recorded.

The same observer also examined all patients. Their height and weight were recorded and the body mass index $\left(\mathrm{wt}(\mathrm{kg}) / \mathrm{ht}\left(\mathrm{m}^{2}\right)\right)$ derived as a measure of obesity. The blood pressure was measured, and patients who were either receiving drugs for hypertension or had a resting diastolic blood pressure of $>90 \mathrm{mmHg}$, or both, were recorded as hypertensive. The distal interphalangeal joints were palpated and nodes recorded as present or absent. A full examination of all limb joints was carried out; joint disease 
was noted as present or absent on a joint chart, and more detailed information recorded from the three principal sites - the hips (range of movement), knee (swelling, range of movement, instability, and tenderness), and hands (swelling, deformity, and tenderness of each joint).

Blood was taken for determination of rheumatoid factor, full blood count, viscosity, and C reactive protein at the time of examination. Further aliquots of serum were stored at $-70^{\circ} \mathrm{C}$, and synovial fluid was obtained from the knee joints of some patients. Standard radiographs were taken of the knees (anteroposterior standing and lateral views) and hands (posteroanterior) in all cases, as well as other symptomatic joint sites.

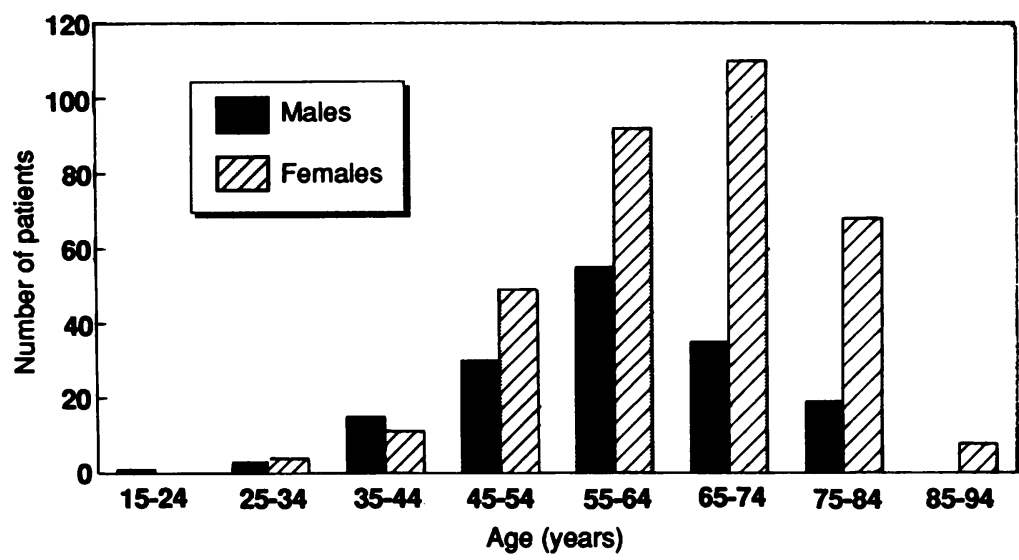

Figure 1 Age-sex distribution of all patients entered into the study.

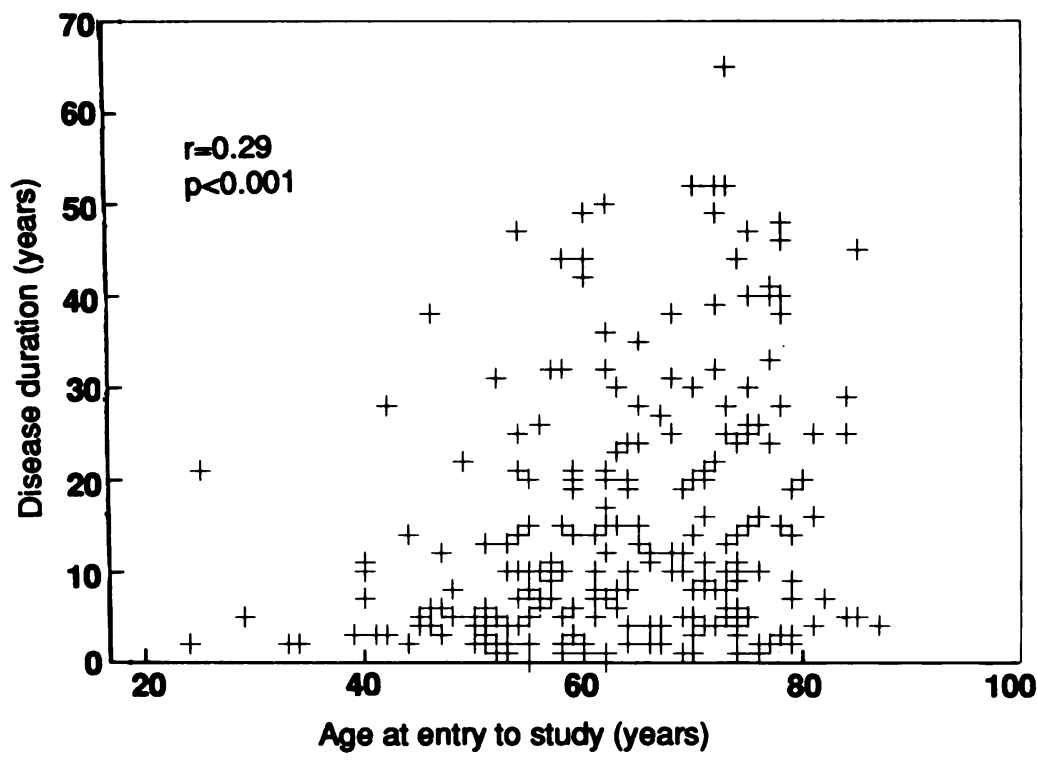

Figure 2 Disease duration plotted against age of entry, showing a weak correlation between symptom duration and increasing age.
Each case record was then reviewed by the two authors, with the radiographs available. Painful joint sites accompanied by typical radiographic changes of osteoarthritis - that is, both joint space narrowing and subchondral bone reaction in any part of the site, were coded as the index joint sites. Data were only collected for limb joints-hips, knees, ankles, feet, shoulders, elbows, wrists, hands. Disease of the first metatarsophalangeal joint was not studied because of the difficulty in establishing, recording, and interpreting the presence of hallux valgus, halux rigidus, and other changes. Back disease was not included in the analysis.

\section{Results}

AGE, SEX, DISEASE DURATION

The study group comprised 342 women and 158 men aged 24 to 88, with a mean of 65.3 years for women and 59.7 for men. Figure 1 shows the age-sex distribution by decade, and illustrates the peaks for men in the 55-64 age group and women in the 65-74 age group. Most patients reported that symptoms had been present in the index joint sites for a long time before referral; the mean symptom duration was 15.4 years with a range of 0-65 years. Figure 2 shows the relation between age at examination and disease duration. It suggests that older patients had the longest disease duration. In many cases, however, it was difficult to establish the time of onset of symptoms in the joint sites of interest, and true symptomatic disease duration was often uncertain.

\section{JOINT DISTRIBUTION}

A total of 847 painful, radiographically abnormal joint sites were recorded, of which $349(41 \cdot 2 \%)$ were knees, 254 (30\%) hands, and 161 (19\%) hips. The other $83(9 \cdot 8 \%)$ symptomatic sites affected included, in order of frequency, ankles/ subtalar joints, shoulders, elbows, wrists, and midtarsal joints.

Two hundred and thirty six $(47 \cdot 2 \%)$ patients had only one symptomatic joint site, of whom only $31(6 \%)$ had unilateral (monoarticular) disease. Single site disease was commoner in men $(97 / 158(61 \%))$ than in women $(139 / 342$ $(40.6 \%))$ and decreased in prevalence with increasing age, as shown in table 1 and figs $3 A$ and $B$. The chief sites of lone osteoarthritis were, in order of prevalence, the knee, hand, and hip. Hand disease showed a strong female preponderance $(4 \cdot 2: 1)$ and hip disease a male bias $(2 \cdot 4: 1)$, whereas knee disease had a roughly equal sex distribution (F:M 1/3:1). Only 17 patients had other joints affected as the only

Table 1 Number of sites affected by osteoarthritis in men and women at different ages

\begin{tabular}{|c|c|c|c|c|c|c|c|c|c|c|c|c|}
\hline & \multicolumn{6}{|l|}{ Women } & \multicolumn{6}{|l|}{ Men } \\
\hline & $\begin{array}{l}\text { Total } \\
\text { No (\%) }\end{array}$ & $\leqslant 44$ & $45-54$ & $55-64$ & $65-74$ & $\geqslant 75$ & $\begin{array}{l}\text { Total } \\
\text { No (\%) }\end{array}$ & $\leqslant 44$ & $45-54$ & $55-64$ & $65-74$ & $\geqslant 75$ \\
\hline Total numbers & 342 & 15 & 49 & 91 & 111 & 76 & 158 & 19 & 30 & 54 & 36 & 19 \\
\hline $\begin{array}{l}1 \text { Joint site unilateral } \\
1 \text { Joint site bilateral } \\
2 \text { Joint sites } \\
3 \text { Joint sites } \\
4+\text { Joint sites }\end{array}$ & $\begin{array}{c}10(2 \cdot 9) \\
129(38) \\
141(41) \\
49(14) \\
13(3 \cdot 8)\end{array}$ & $\begin{array}{r}2 \\
10 \\
3 \\
0 \\
0\end{array}$ & $\begin{array}{r}4 \\
28 \\
12 \\
4 \\
1\end{array}$ & $\begin{array}{r}2 \\
44 \\
37 \\
6 \\
2\end{array}$ & $\begin{array}{r}2 \\
31 \\
56 \\
17 \\
5\end{array}$ & $\begin{array}{r}0 \\
16 \\
33 \\
22 \\
5\end{array}$ & $\begin{array}{l}21(13) \\
76(48) \\
41(26) \\
15(9) \\
5(3)\end{array}$ & $\begin{array}{r}7 \\
10 \\
2 \\
0 \\
0\end{array}$ & $\begin{array}{r}5 \\
17 \\
6 \\
2 \\
0\end{array}$ & $\begin{array}{r}7 \\
27 \\
13 \\
4 \\
3\end{array}$ & $\begin{array}{r}2 \\
11 \\
15 \\
7 \\
1\end{array}$ & $\begin{array}{r}0 \\
11 \\
5 \\
2 \\
1\end{array}$ \\
\hline
\end{tabular}



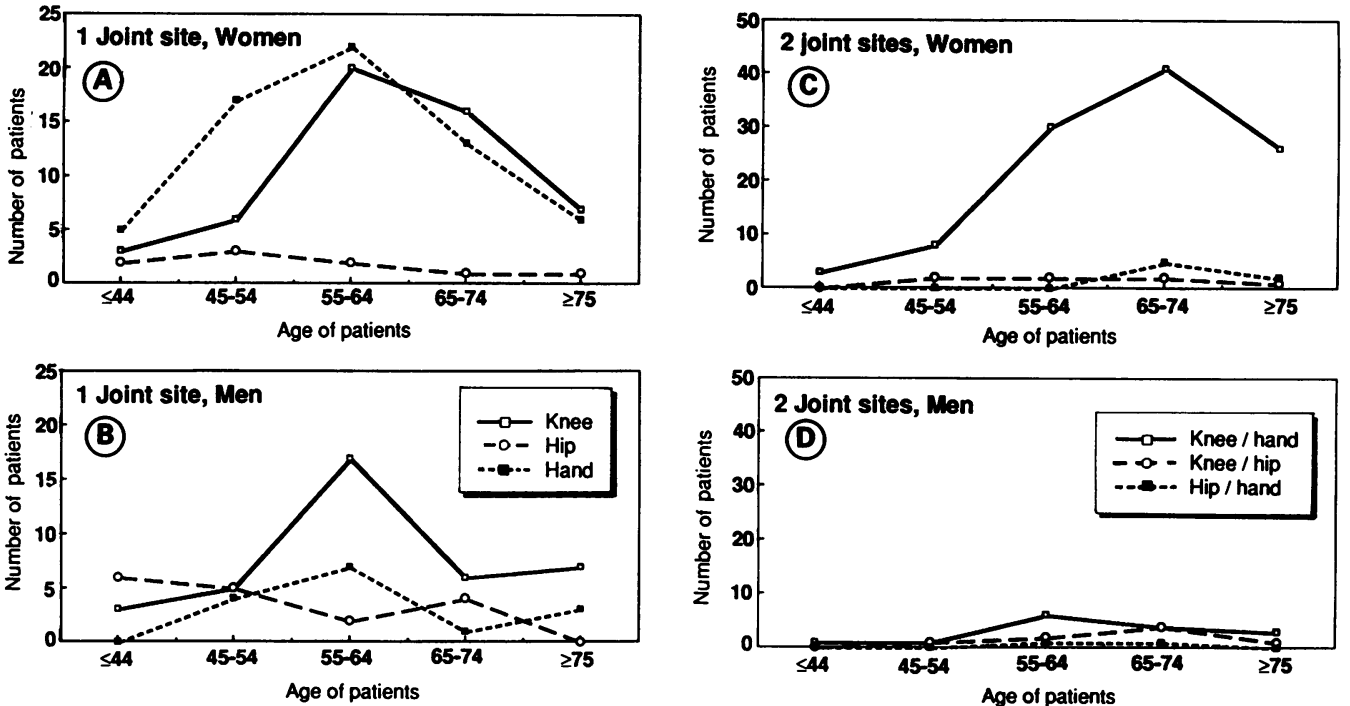

Figure 3 Number of patients with one or two major joint sites affected at different ages.

symptomatic sites; 11 were men, and the joints affected were ankles (eight), shoulders (five), elbows (two), wrists and midtarsal joints (one each).

Disease of joints at two different sites was recorded in 182 patients $(36.4 \%)$, of whom 141 were women. This group was dominated by women with a combination of knee and hand disease (108 patients, $21.6 \%$ of all patients) (figs $3 \mathrm{C}$ and $\mathrm{D}$ ). Analysis of the correlations between osteoarthritis at the three major joint sites (knees, hands, hips) in this group showed a statistically significant association between hand and knee disease in women but no relation between hand and hip or knee and hip disease in either sex or in the whole group (table 2). Sixty four patients $(12 \cdot 8 \%)$ had three symptomatic joint sites, of whom 49 were women; only 13 women and five men had four or more sites affected. Table 1 shows the strong correlation between increasing age, female sex, and increasing numbers of affected joints.

Table 2 Associations between two joint sites in men and women

\begin{tabular}{lcllll}
\hline & \multicolumn{3}{l}{ Women } & & Men \\
\cline { 2 - 3 } \cline { 5 - 6 } & Hip & Hand & & Hip & Hand \\
\hline +Knee & 7 & $108(\mathrm{p}<0.001)$ & 9 & $15(\mathrm{NS})$ \\
-Knee & 7 & 13 & 5 & 3 \\
& Knee & Hand & & Knee & Hand \\
+Hip & 7 & 7 (NS) & & 8 & $2(\mathrm{NS})$ \\
-Hip & 121 & 114 & & 25 & 16 \\
\hline
\end{tabular}

$p$ Values for $\chi^{2}$ statistic for one degree of freedom with Yates's correction.

Table 3 Age, sex, and incidence of other affected sites in patients with osteoarthritis involving each of the major limb joints

\begin{tabular}{|c|c|c|c|c|c|}
\hline \multirow[t]{2}{*}{ Joint site } & \multirow[t]{2}{*}{$\%$ Of total } & \multirow[t]{2}{*}{$F: M$ ratio } & \multicolumn{2}{|c|}{ Mean age } & \multirow{2}{*}{$\begin{array}{l}\text { \% Occurring } \\
\text { as only site }\end{array}$} \\
\hline & & & $\boldsymbol{F}$ & $\boldsymbol{M}$ & \\
\hline $\begin{array}{l}\text { Knees } \\
\text { Hands } \\
\text { Hips } \\
\text { Ankles } \\
\text { Shoulders } \\
\text { Elbows } \\
\text { Wrists }\end{array}$ & $\begin{array}{r}41 \cdot 2 \\
30 \cdot 0 \\
19 \cdot 0 \\
4 \cdot 4 \\
3 \cdot 2 \\
1 \cdot 6 \\
0.6\end{array}$ & $\begin{array}{r}1 \cdot 3: 1 \\
4 \cdot 3: 1 \\
0 \cdot 4: 1 \\
0 \cdot 8: 1 \\
3: 1 \\
0 \cdot 25: 1 \\
1: 1\end{array}$ & $\begin{array}{l}62 \cdot 6 \\
59 \cdot 3 \\
54 \cdot 3 \\
57 \cdot 7 \\
69 \cdot 7 \\
62 \cdot 8 \\
75 \cdot 5\end{array}$ & $\begin{array}{l}59.8 \\
61.5 \\
51.3 \\
51.4 \\
61.5 \\
54.5 \\
77.0\end{array}$ & $\begin{array}{l}39 \\
36 \\
58 \\
38 \\
31 \\
20 \\
25\end{array}$ \\
\hline
\end{tabular}

Table 3 shows the prevalence of disease of each major joint site together with the sex ratio, mean age of men and women with each site affected, and incidence of coexisting osteoarthritis at other sites. The overall female preponderance of hand and shoulder disease contrasted with the male bias for hip and elbow disease. The hip was clearly the earliest site affected in both sexes, whereas shoulder disease in women was a later manifestation. Wrist disease was largely seen in elderly patients with chondrocalcinosis, but the number of people with symptoms at this site was very small.

\section{ASSOCIATIONS}

Associations between any apparent predisposing causes, intercurrent rheumatic diseases, obesity, hypertension, Heberden's nodes, and the patterns of osteoarthritis described were sought (table 4).

An obvious predisposing cause was only apparent in 46 cases-28 (18\%) men and 18 (5\%) women. They included severe trauma, menisectomy, epiphysial dysplasia, and instability. 'Secondary' osteoarthritis was commonest in men, younger patients, and those with one large joint site affected. It was recorded in $20 \%$ of hips, $27 \cdot 5 \%$ of knees and $37 \cdot 5 \%$ of those with the less common sites (ankles, shoulders etc) as their only symptomatic joints.

Seventy two patients $(14 \cdot 4 \%)$ had some other disorder of the musculoskeletal system in addition to their osteoarthritis. There was a wide spectrum of such conditions, of which the commonest was gout (12 men, $2 \cdot 4 \%$ ). In each case it was thought they were associated conditions rather than causes of the osteoarthritis, and they were commonest in the older patients. Eleven patients $(2 \cdot 2 \%)$ with definite or classical rheumatoid arthritis (American Rheumatism Association criteria ${ }^{7}$ ) were entered into the study. In each case the rheumatoid arthritis had developed after the onset of symptomatic osteoarthritis, and the latter was still considered to be the principal problem.

The most common extra-articular associations were hypertension and obesity (table 4). Hyper- 
Table 4 Associations between apparent predisposing causes, intercurrent rheumatic diseases, obesity, hypertension, Heberden's nodes, and the patterns of osteoarthritis

\begin{tabular}{|c|c|c|c|c|c|c|c|c|c|}
\hline & \multirow[t]{2}{*}{$n$} & \multirow{2}{*}{$\begin{array}{l}\text { Obvious } \\
\text { secondary } \\
\text { cause (\%) }\end{array}$} & \multirow{2}{*}{$\begin{array}{l}\text { Knee } \\
\text { chondrocalcinosis } \\
\text { (\%) }\end{array}$} & \multirow{2}{*}{$\begin{array}{l}\text { Erosions } \\
(\%)\end{array}$} & \multirow{2}{*}{$\begin{array}{l}\text { Heberden's } \\
\text { nodes } \\
(\%)\end{array}$} & \multirow{2}{*}{$\begin{array}{l}\text { Obesity } \\
(Q \geqslant 30)^{*} \\
(\%)\end{array}$} & \multirow{2}{*}{$\begin{array}{l}\text { Hypertension } \\
(\%)\end{array}$} & \multicolumn{2}{|l|}{ Steinbrocker } \\
\hline & & & & & & & & $\begin{array}{l}\text { Class 1-2 } \\
(\%)\end{array}$ & $\begin{array}{l}\text { Class 3-4 } \\
(\%)\end{array}$ \\
\hline $\begin{array}{l}\text { Total } \\
\text { Total women } \\
\leqslant 64 \text { years } \\
\geqslant 65 \text { years } \\
\text { Total men } \\
\leqslant 64 \text { years } \\
\geqslant 65 \text { years } \\
\text { One joint site: }\end{array}$ & $\begin{array}{r}500 \\
342 \\
155 \\
187 \\
158 \\
103 \\
55\end{array}$ & $\begin{array}{r}9 \\
5 \\
7 \\
4 \\
18 \\
21 \\
11\end{array}$ & $\begin{array}{r}18 \\
17 \\
6 \\
26 \\
22 \\
21 \\
24\end{array}$ & $\begin{array}{r}5 \\
6 \\
11 \\
3 \\
1 \\
2 \\
0\end{array}$ & $\begin{array}{l}48 \\
56 \\
53 \\
59 \\
30 \\
28 \\
33\end{array}$ & $\begin{array}{l}13 \\
13 \\
17 \\
10 \\
15 \\
14 \\
16\end{array}$ & $\begin{array}{l}37 \\
37 \\
32 \\
42 \\
37 \\
38 \\
36\end{array}$ & $\begin{array}{l}66 \\
63 \\
81 \\
48 \\
72 \\
78 \\
62\end{array}$ & $\begin{array}{l}31 \\
35 \\
17 \\
50 \\
23 \\
16 \\
34\end{array}$ \\
\hline $\begin{array}{l}\text { Knee } \\
\text { Hip } \\
\text { Hand } \\
\text { Other }\end{array}$ & $\begin{array}{r}105 \\
37 \\
78 \\
16\end{array}$ & $\begin{array}{r}15 \\
19 \\
0 \\
31\end{array}$ & $\begin{array}{r}27 \\
5 \\
8 \\
37\end{array}$ & $\begin{array}{r}0 \\
0 \\
15 \\
0\end{array}$ & $\begin{array}{r}19 \\
5 \\
70 \\
37\end{array}$ & $\begin{array}{r}16 \\
22 \\
11 \\
6\end{array}$ & $\begin{array}{l}38 \\
22 \\
33 \\
25\end{array}$ & $\begin{array}{l}73 \\
73 \\
74 \\
69\end{array}$ & $\begin{array}{l}24 \\
27 \\
17 \\
31\end{array}$ \\
\hline $\begin{array}{l}\text { Two joint sites: } \\
\text { Knee/hand } \\
\text { Knee/hip } \\
\text { Hip/hand }\end{array}$ & $\begin{array}{r}123 \\
16 \\
9\end{array}$ & $\begin{array}{r}3 \\
31 \\
22\end{array}$ & $\begin{array}{l}13 \\
25 \\
22\end{array}$ & $\begin{array}{l}6 \\
0 \\
0\end{array}$ & $\begin{array}{r}71 \\
6 \\
78\end{array}$ & $\begin{array}{r}16 \\
37 \\
0\end{array}$ & $\begin{array}{l}41 \\
19 \\
44\end{array}$ & $\begin{array}{l}63 \\
44 \\
67\end{array}$ & $\begin{array}{l}32 \\
50 \\
33\end{array}$ \\
\hline
\end{tabular}

${ }^{*} \mathrm{Q}=\mathrm{wt}(\mathbf{k g}) / \mathrm{ht}\left(\mathrm{m}^{2}\right)$.

tension, as defined, was recorded in 128 women (37\%) and 59 men (37\%). There was no apparent association with the patterns of osteoarthritis. Subjects with a body mass index of $>25$ were considered to be overweight, those over 30 obese. A total of 172 women $(50 \%)$ and 96 men $(60 \%)$ were overweight, of whom 52 women and 26 men were obese (15.5\%). This feature was commoner in the younger women rather than the older women (table 4). Those with obesity tended to have only one or two sites affected, the commonest joints being knees (17), hands (nine), hips (eight), knees +hands (21), and knees thips (13). Six of 16 patients (37\%) with the combination of hip and knee disease had a body mass index of $>30$, and $71 \%$ were overweight. Those with lone hand disease tended to have a lower than average incidence of obesity $(11 \cdot 5 \%)$.

Heberden's nodes were found in 193 women (56\%) and 47 men (30\%). There was no apparent association between this finding and age. Nodes were not uncommon in those without symptomatic hand disease, occurring in 28 of 158 patients $(18 \%)$ with lone involvement of one large joint site. They were found in only $5.5 \%$ of those with hip disease, $19 \%$ of those with knee joint disease, and $37.5 \%$ of those with other symptomatic large joints.

\section{INVESTIGATIONS}

Haematological investigations were unremarkable. A slightly raised plasma viscosity was common, but the $\mathrm{C}$ reactive protein was above the upper limit of normal of $10 \mathrm{mg} / \mathrm{l}$ in only 50 women (15\%) and 23 men (15\%). Thirty five patients had a rheumatoid factor titre of $>1 / 40$, including the 11 with known rheumatoid arthritis. Raised $\mathrm{C}$ reactive protein and rheumatoid factor titres correlated with age, female sex, and the presence of an intercurrent inflammatory disorder, but showed no correlations with patterns of osteoarthritis.

Two specific radiological features were recorded as present or absent and related to the known osteoarthritis: they were knee chondrocalcinosis and interphalangeal joint erosions. Erosions, defined as breaks in the cortex of subchondral bone, were seen in the interphalangeal joints in only 24 cases ( 22 women, mean age 57.5 years). Chondrocalcinosis was present in 57 women (17\%) and 35 men (22\%). It correlated with increasing age and the presence of knee osteoarthritis; 28/105 (27\%) of those with lone knee disease had chondrocalcinosis, compared with only 13/131 (10\%) with isolated disease of other joint sites.

\section{FUNCTION}

The Steinbrocker functional class was used as a crude measure of disability. ${ }^{8}$ As shown in table 4 functional classes 3 or 4 were recorded most often in elderly women. As might be expected, poor function also correlated with lower limb disease and multiple joint sites affected. One hundred and fifty five (31\%) of all patients were in functional classes 3 or 4 , and a further 262 $(52.5 \%)$ were in functional class 2 , giving some indication of the severity of osteoarthritis being studied. A total of 165 patients (33\%) were recorded as using aids and appliances, usually a walking aid. Three hundred and seventy four (74.8\%) were taking non-steroidal antiinflammatory drugs or analgesics, or both, for their osteoarthritis at the time of assessment.

\section{Discussion}

It is widely recognised that osteoarthritis is the most important form of joint disease contributing to the overall health burden of the community. ${ }^{1}$ There has been less clinical research into osteoarthritis than into many other, much rarer forms of rheumatic disease, however. This may be explained in part by the relative lack of severity of osteoarthritis in comparison with systemic inflammatory arthropathies, and because a minority of patients with osteoarthritis are referred to specialist rheumatologists. ${ }^{9}$ As a result we still lack definitive data on many simple facets of osteoarthritis, such as its patterns of joint distribution, possible disease subsets, and natural history. Two main subsets are recognised, monoarticular secondary osteoarthritis, resulting from congenital or acquired 
abnormalities of joint shape, and generalised 'nodal' osteoarthritis, characterised by polyarticular disease affecting the hand. ${ }^{10}$ The validity of even these subsets is arguable, ${ }^{6} 11$ however, and the definition, classification, and diagnostic criteria of the disease also remain controversial. ${ }^{12}$

This paper reports the cross-sectional data obtained from 500 patients diagnosed as having peripheral joint osteoarthritis in a hospital based rheumatology unit. The purpose of this report is to examine the hypothesis that subsets of osteoarthritis can be defined by demography and joint distribution, and to examine the validity of the concept of a generalised form of osteoarthritis. To that end the associations and interrelations of osteoarthritis at each of the major peripheral joint sites have been recorded.

The patient group is unlikely to be representative of osteoarthritis in the community. The patients were all referred to consultant rheumatologists in Bristol or Bath, and then channelled to the one local unit with a special interest in the disease. They may well have more severe osteoarthritis, or be more demanding people, than most; they may exclude an important group referred directly to orthopaedic surgeons. If a large number are examined, however, some examples of most of the important manifestations of the condition should be included. Furthermore, the age and sex distribution of our patients is not inconsistent with that of other hospital surveys, ${ }^{13}$ and similar to that seen in community based studies of osteoarthritis, ${ }^{3}$ suggesting that our patients are not entirely unrepresentative of the problem as a whole. An overall female preponderance and a wide range of age of onset with a mean around the sixth or seventh decade has been described in other studies. ${ }^{45}$ The data reported here provide a comparison of patients of different age, sex, or joint complaints. This was facilitated by careful data collection. Entry to the study was controlled by one of the authors (PD), and the historical and examination data were all collected by the other (JC). As a result, any apparent differences in associations between patient groups should be of value, though the absolute numbers with a particular feature cannot be regarded as meaningful.

For the purposes of this study osteoarthritis was diagnosed if the patient complained of pain related to joint usage, if the radiographs of that joint(s) showed evidence of osteoarthritis (including joint space narrowing), and if there was no other apparent cause of symptoms. In the absence of established diagnostic criteria ${ }^{12}$ there are few alternatives. Spinal disease was excluded because of the difficulty in defining spinal osteoarthritis and of relating radiographs to symptoms, ${ }^{14}$ and the first metatarsophalangeal joint was omitted from the analysis for similar reasons. This limits the study and makes it difficult to relate it to published data which, for example, stress spinal disease in generalised osteoarthritis. ${ }^{15}$ The data collected were designed to maximise information on the major joint sites said to be affected in osteoarthritis (knees, hands, and hips), and some of the main risk factors and associations previously reported. ${ }^{34}$
It is apparent that the group as a whole had significant disease, as shown by the high rates of drug use, dependence on aids and appliances, and the number of patients with a Steinbrocker index of 3 or 4. Not surprisingly, age and lower limb disease correlated strongly with the greater degrees of disability.

The joint disease seen in our patients was much as we expected, being dominated by knee, hand, and hip problems, in that order. Hip disease may well be underrepresented, because of the tendency among local practitioners to refer this condition directly to surgeons. The interrelations between these three sites show a strong association between hand and knee disease, but not between hips and hands, or hips and knees. The hip stands out as a site with quite different associations, being more likely to occur as a lone problem in younger, non-obese men than disease at other joint sites. Elbow disease also emerged as having a male preponderance, as recently described elsewhere. ${ }^{16}$ In contrast, problems at the shoulder tended to occur in older women. The other strong trend to emerge is of more sites of disease, more severely affected, as age advances. The association of numbers of joint sites with age might be explained by slow addition of new sites, as suggested in another study in a similar population, ${ }^{17}$ or by older subjects having a greater predisposition to osteoarthritis at unusual sites. The prospective data on this group should help resolve this further, but if, as seems likely, it is due to slow addition of new sites, then it is important to recognise that the diagnosis of 'generalised' osteoarthritis would depend on the time point in the disease evolution at which a particular patient was seen. The absence of older men in the group might be due to earlier death, or be an ascertainment artefact-that is, we might not have seen a representative selection of patients as we recruited only patients referred to a rheumatologist. Prospective data should show whether osteoarthritis develops differently in men and women with time.

The disease associations included a significant number with another rheumatic disease, which probably represents an ascertainment artefact. In contrast, few had a clear cut 'cause' for their osteoarthritis. This low incidence of 'secondary' osteoarthritis is at variance with some studies, though patient series not dominated by hip osteoarthritis rarely report a high incidence of an obvious cause. ${ }^{101318} 19$ Our data support the idea that secondary osteoarthritis is an uncommon form of the condition, principally seen in younger men with hip, knee, or ankle/subtalar disease related to abnormalities of joint shape or previous trauma. A combination of hip and knee disease was unusual, but often associated with a predisposing cause or obesity, or both, in our series. The high incidence of subjects with osteoarthritis who were overweight or obese accords with other data ${ }^{3}$; the findings that this was not associated with age or related to numbers of sites affected or disability suggests that it is a genuine risk factor or association, and not a result of osteoarthritis. ${ }^{20}$ Although we have no control data, the incidence 
of obesity in our series is much higher than that found in a recent United Kingdom community survey. 21

Heberden's nodes are often used as a marker of so called generalised or nodal osteoarthritis. ${ }^{1522}$ Population surveys suggest, however, that they become extremely common in older women, with a far higher incidence than that of symptomatic osteoarthritis. ${ }^{23}$ In this series they were usually, but not always, seen in those with hand disease. They were also commonly present in those with osteoarthritic knees and other symptomatic joint sites (except the hips and ankles) who did not have hand problems. This strengthens the data indicating that hip osteoarthritis behaves differently from that of other sites, but it undermines the concept of a distinct subset of nodal osteoarthritis. The high incidence of multisite disease associated with being overweight, hypertensive, and having Heberden's nodes suggests that most subjects with osteoarthritis have a background systemic predisposition to their disease, resulting in localisation to a limited number of joint sites which is associated with age. Age was also the main association of chondrocalcinosis and abnormalities of blood tests, none of which showed any clear relation with disease at a particular joint site(s). Previous reports of distinctive forms of inflammatory, erosive, or generalised osteoarthritis may reflect disease severity rather than specific subsets. ${ }^{24}$

The most significant finding is the strong statistical association between knee and hand disease in women. This indicates that the distribution of osteoarthritis, although dependent on age and sex, is not random. It is also strong evidence for a major generalised or systemic component in the aetiology of many cases of osteoarthritis.

This work is supported by the Arthritis and Rheumatism Council. We would like to thank Mrs Sara Browning for organisational and secretarial help, and consultant colleagues for allowing us to study their patients.
1 Lawrence R C, Hochberg M C, Kelsey J L, et al. Estimates of the prevalence of selected arthritic and musculoskeletal diseases in the United States. $\mathcal{F}$ Rheumatol 1989; 16: 427-41.

2 Wood P H N, Badley E M. Epidemiology of individual rheumatic disorders. In: Scott J T, ed. Copeman's textbook of the rheromatic diseases. 6th ed. Edinburgh and London: Churchill Livingstone, 1986: 59-142.

3 Felson D T. Epidemiology of hip and knee osteoarthritis. Epidemiol Rev 1988; 10: 1-28.

4 Scott J C, Hochberg M C. Osteoarthritis: 1. Epidemiology. Maryland State Medical foumal 1984; 33: 712-6.

5 Peyron J G. The epidemiology of osteoarthritis. In: Moskowitz R W, Howell D S, Goldberg V M, Mankin H S, eds. Osteoarthritis: diagnosis and management. Saunders: PhilaOsteoarthritis: diagnosis and managent

6 Doherty M, Watt I, Dieppe P. Influence of primary generalised osteoarthritis on development of secondary osteoarthritis. Lancet 1983; ii: 8-11.

7 Arnett F C, Edworthy S M, Bloch D A, et al. The American Rheumatism Association 1987 revised criteria for the classification of rheumatoid arthritis. Arthritis Rheum 1988; 31: 315-24.

8 Steinbrocker O, Traeger C H, Batterman R C. Therapeutic criteria in rheumatoid arthritis. $\mathcal{F A M A} 1949 ; 140$ : 659-62.

9 Hadler N M. Osteoarthritis as a public health problem. Clin Rheum Dis 1985; 11: 175-85.

10 Mitchell N S, Cruess R L. Classification of degenerative arthritis. Can Med Assoc $\mathcal{J}$ 1977; 117: 763-5.

11 Wood P H N. Osteoarthritis in the community. Clin Rheum Dis 1976; 2: 495-507.

12 McAlindon T, Dieppe P. Osteoarthritis: definitions and criteria. Ann Rheum Dis 1989; 48: 531-2.

13 Huskisson E C, Dieppe P A, Tucker A K, Cassell B. Another look at ostecarthritis. Ann Rheum Dis 1979; 38: 423-8.

14 Lawrence J S, Bremner J M, Bier F. Osteoarthritis: prevalence in the population and relationship between symptoms and x-ray changes. Ann Rhewm Dis 1966; 25: $1-24$.

15 Kellgren J H, Moore R. Generalised osteoarthritis and Heberden's nodes. Br Med f 1952; i: 181-4.

16 Doherty M, Preston B. Primary osteoarthritis of the elbow. Ann Rhewon Dis 1989; 48: 743-7.

17 Massardo L, Watt I, Cushnaghan J, Dieppe P. An eight year prospective study of osteoarthritis of the knee joint. Ann Rhewom Dis 1989; 48: 893-7.

18 Meachim G, Whitehouse G H, Pedley R B, Nichol F E, Owen $R$. An investigation of radiological, clinical and pathological correlations in osteoarthritis of the hip. Clin Radiol 1980; 31: 565-74. 19 Harris W. Etiology of osteoarthritis of the hip. Clin Orthop

20 Van Saase J L C M, Vandenbroucke J P, van Romande L, Valkenburg H A. Osteoarthritis and obesity in the general population. A relationship calling for an explanation. f Rheumatol 1988; 15: 1152-8.

21 Royal College of Physicians. Obesity. F R Coll Physicians Lond 1983; 17: 5-65.

22 YaziciH,SavilleP D, SalvatiEA, et al. Primary osteoarthritis of the knee or hip-prevalence of Heberden's nodes in relation to age and sex. $\mathcal{F} A M A$ 1975; 231: 1256-60.

23 Lawrence J S. Rheumatism in populations. London: Heinemann, 1977.

24 Cobby M, Cushnaghan J, Creamer P, Dieppe P, Watt I. Erosive osteoarthritis: Is it a separate disease entity? Clin Radiol (in press). 